\title{
Sexual and Reproductive Health Knowledge: Empowering Women through Social Determinants of Health
}

\author{
Melanie Hanna-Johnson, MHSA, Lucki Word, Anil N. F. Aranha
}

Publisher's Note: MDPI stays neutral with regard to jurisdictional claims in published maps and institutional affiliations.

\section{(c) (P)}

Copyright: $@ 2021$ by the authors. Submitted for possible open access publication under the terms and conditions of the Creative Commons Attribution (CC BY) license (http://creativecommons.org/licenses/by/4.0/).
Departments of Internal Medicine, Office of Diversity and Inclusion, and Office of Medical Education, Wayne State University School of Medicine, Detroit, MI 48201, U.S.A.

\begin{abstract}
Purpose: The COVID-19 pandemic dynamic of sheltering-in-place affords possible opportunities to address social determinants of health $(\mathrm{SDOH})$, as they relate to sexual and reproductive health knowledge (S\&RHK). Strategic and crucial opportunities might exist for educational interventions by caregivers engaging in more frequent and prolonged encounters with young people. The purpose of this study was to evaluate whether two social determinants of health, income and education, are associated with sexual and reproductive health knowledge among adult women. Methods: A 50-item survey was administered to women, aged 20-89 years, in two outpatient, metropolitan, primary care clinics in the United States. 18 of the 50 questions gauged S\&RHK, and had only one correct answer. The maximal attainable score was 18. Data was coded and analyzed using IBM-SPSS. Statistical analysis included: Pearson correlation, $t$, and Chi-squared tests. Statistical significance was established at $\mathrm{p}<0.05$. Results: 287 women, with a mean age of $55.3 \pm 14.2$ years, were surveyed. The majority (85.7\%) were African-American, with $66 \%$ having incomes $\leq \$ 50,000$. Average years of formal education were $14.1 \pm 2.5$.The mean S\&RHK score was $10.2 \pm 3.6$, on a scale of $0-18$. Of those with formal sex education, $43.5 \%$ stated it was sufficient. $32 \%$ reported no history of formal sex education. $97 \%$ reported that having sufficient S\&RHK was important. Positive correlations were found between years of education, income, and S\&RHK scores $(p<0.001)$; a negative correlation between age and S\&RHK scores $(p<0.001)$. Conclusions: $S \& R H K$ was strongly associated with education and income: two SDOH. Older women, irrespective of income, were found to score lower. Educational attainment seemed to have been the discriminating factor in this demographic. All three may figure prominently into an assessment of the effects of social accountability (i.e. the micro-, meso-, and macro- elements of social determinants of health) on health outcomes.
\end{abstract}

